\title{
Experimental investigation of compact silicon carbide heat exchangers for high temperatures
}

\author{
Thomas Fend ${ }^{a}$, Wilhelm Völker ${ }^{b}$, Rolf Miebach ${ }^{c}$, Olena Smirnova ${ }^{\mathrm{a}, *}$, Daniel Gonsior ${ }^{\mathrm{d}}$, Daniel Schöllgen ${ }^{\mathrm{a}}$, \\ Peter Rietbrock ${ }^{\text {a }}$ \\ ${ }^{a}$ German Aerospace Center, Institute of Technical Thermodynamics, Linder Höhe, 51147 Köln, Germany \\ ${ }^{\mathrm{b}}$ Saint Gobain Industriekeramik Rödental GmbH, Postfach 1144, 96466 Rödental, Germany \\ ${ }^{c}$ Deutz AG, Ottostraße 1, 51149 Köln, Germany \\ ${ }^{\mathrm{d}}$ Solar-Institut Jülich, Heinrich-Mußmann-Straße 5, 52428 Jülich, Germany
}

\section{A R T I C L E I N F O}

Article history:

Received 12 October 2010

Received in revised form 6 May 2011

Accepted 24 May 2011

\section{Keywords:}

Compact heat exchanger

Silicon carbide

High temperature

\begin{abstract}
A B S T R A C T
The results of experimental investigations of novel ceramic high-temperature heat exchangers (HTHE) and its main characteristics such as effectiveness and power load as a function of mass flow and the geometry of the channels are presented. Firstly, some information on the background and the manufacturing of the HTHE, which is based on honey comb structures made out of extruded silicon carbide, is given. The experimental tests have been carried out with air as a heat transfer medium at temperatures of up to $1000^{\circ} \mathrm{C}$. The experimental set-up is described in detail. The acquired characteristic temperature and effectiveness data for different inlet temperatures and mass flows are discussed. They have been compared with data from theoretical calculations as well as with characteristic data of typical counter flow heat exchangers. Additionally, thermal shock tests have been carried out for a qualitative testing of the mechanical strength. Finally, a conclusion and an outlook on further activities are given.
\end{abstract}

(c) 2011 Elsevier Ltd. All rights reserved.

\section{Introduction}

Extruded silicon carbide ( $\mathrm{SiC}$ ) honeycomb structures have been mainly used as particle filters in automotive applications [1]. Extruded $\mathrm{SiC}$ is also known as fuel elements for nuclear power stations [2]. Since 1995, an increasing interest in extruded SiC was arising from the application as a solar air receiver for concentrating solar power technology (CSP). A receiver system has been developed, which aims at transferring heat from concentrated radiation to an air circuit, which feeds the boiler of a steam turbine [3]. In this application especially the excellent resistance to thermal shocks as well as the high thermal conductivity of the material is of great advantage.

From this application and taking the extruded 2D honeycomb structure as a basis, the idea of creating an advanced geometry for a heat exchanger has been developed. The extruded structure consists of square channels. The special structure of the heat exchanger has been realized by cutting $20 \mathrm{~mm}$ slots in every second row of channels (Fig. 1). After that the front openings of these slots have been filled with ceramic material. In this way two systems of channels have been created. One system of parallel channels going from the one front side to the other and one system of channels,

\footnotetext{
* Corresponding author. Tel.: +492203601 2901.

E-mail address: olena.smirnova@dlr.de (O. Smirnova).
}

which can be entered from the lateral openings of the slots. In the further course of the text these two systems of channels are denoted "straight" and "slotted" channels respectively. In this way two independent fluids, which are separated by ceramic walls, can flow through the HE. Thus it can be used as a recuperator type counterflow heat exchanger. Two heat exchangers both consisting of square channels were used for the investigations. Channel width and wall thickness have been varied. The samples had a channel width/wall thickness ratio of $2 \mathrm{~mm} / 0.8 \mathrm{~mm}$ and $2.17 \mathrm{~mm} / 0.6 \mathrm{~mm}$ respectively (samples 1 and 2 ).

The heat exchanger was investigated in the context of a project dealing with filter systems for diesel exhaust after treatment components. One possible application is the use of this heat exchanger in the exhaust after treatment of diesel engines in bi-functional way. It is used as a catalyst as well as an additional heat source for the regeneration of the filter. This application is shown in Fig. 2 schematically. The technology presented must be distinguished from micro-heat exchangers for cooling purposes, which mainly work with high pressures or liquid media [4-7]. Though having benefitted from a rapid development especially in manufacturing technology, these systems may not be applied in exhaust after treatment systems due to their different permeability properties.

For a further comparison, investigations on the thermal performance of those systems may be found in [8,9]. 


\begin{tabular}{|c|c|c|c|}
\hline \multicolumn{4}{|c|}{ Nomenclature } \\
\hline$A$ & surface, $\mathrm{m}^{2}$ & $\lambda$ & heat conductivity coefficient, $\mathrm{W} / \mathrm{m} \mathrm{K}$ \\
\hline$c_{p}$ & specific heat capacity, $\mathrm{kJ} / \mathrm{kg} \mathrm{K}$ & $\Delta$ & difference between the variables, $\mathrm{kg} / \mathrm{m}^{3}$ \\
\hline$f$ & surface of the cross-section, $\mathrm{m}^{2}$ & $\phi$ & degree of the heat efficiency, - \\
\hline$k$ & heat transfer coefficient, $\mathrm{W} / \mathrm{m}^{2} \mathrm{~K}$ & & \\
\hline $\bar{k}$ & overall heat transfer coefficient, $\mathrm{W} / \mathrm{m}^{2} \mathrm{~K}$ & \multicolumn{2}{|l|}{ Indices } \\
\hline NTU & number of heat transfer unit, - & 2 & secondary medium \\
\hline$Q$ & heat flux, $\mathrm{W}$ & i & inlet \\
\hline$t$ & temperature, ${ }^{\circ} \mathrm{C}$ & " & outlet \\
\hline$T$ & thermodynamic temperature, $\mathrm{K}$ & & \\
\hline$u$ & velocity, $\mathrm{m} / \mathrm{s}$ & \multicolumn{2}{|c|}{ Dimensionless numbers } \\
\hline$a$ & thermal diffusivity, $\mathrm{m}^{2} / \mathrm{s}$ & $N u_{\mathrm{m}}$ & average Nusselt number for undeveloped flow \\
\hline$\alpha$ & convective heat transfer coefficient, $\mathrm{W} / \mathrm{m}^{2} \mathrm{~K}$ & & \\
\hline$\varepsilon$ & efficiency, - & & \\
\hline$\delta$ & thickness of the wall, $\mathrm{m}$ & & \\
\hline
\end{tabular}

The heat exchanger investigated in this study has a specific surface areas of approximately $750 \mathrm{~m}^{2} / \mathrm{m}^{3}$ with the possibility of high overall heat transfer coefficients $\left(30-50 \mathrm{~W} / \mathrm{m}^{2}\right.$ for gas/gas heat exchange) and the option to be operated at temperatures of up to $980{ }^{\circ} \mathrm{C}[10,11]$.

\section{Manufacturing}

Requirements on material design for heat exchangers are gas tightness, high thermal conductivity, low specific weight and high corrosion resistance. These properties are fulfilled by silicon carbide $(\mathrm{SiC})$ technical ceramics which are produced in a wide variety of types. Depending on structure and ceramic bonding, SiC ceramics can be classed as porous $\mathrm{SiC}$ materials, such as silicate bonded,

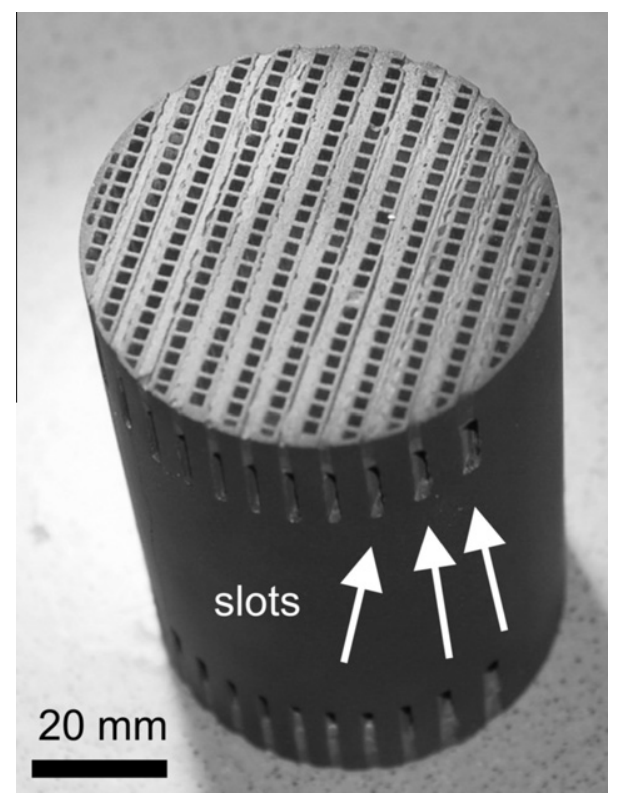

Fig. 1. Heat exchanger from extruded silicon carbide. recrystallized or nitride bonded $\mathrm{SiC}$, or dense $\mathrm{SiC}$ materials, like reaction bonded infiltrated or sintered SiC.

The material selected for production of honey comb heat exchangers is reaction bonded infiltrated silicon carbide ( $\mathrm{SiSiC}$ ). It is typically composed of $80-94 \% \mathrm{SiC}$ and $6-20 \%$ metallic silicon and, in contrast to sintered $\mathrm{SiC}$, can be manufactured without shrinkage - an advantage for manufacturing parts with precise dimensions.

The production flow comprises three steps, the shaping of a green body, machining and sintering.

A mix of SiC powders, carbon and organic binders are shaped in a screw or piston extruder by pressing the material through a honeycomb die. The continuous body is cut into the desired length. During drying, organic binders ensure the mechanical stability of the green body.

The dried product is stable enough to be machined (i.e. drilling, precise cutting, milling or sawing slots, etc.) to its final shape.

For sintering the $\mathrm{SiC} /$ carbon body is infiltrated with metallic silicon. The reaction with the liquid silicon and the carbon generates a $\mathrm{SiC}$ bonding between $\mathrm{SiC}$ grains. The remaining pore volume is filled with metallic silicon creating a fully dense $\mathrm{Si}-\mathrm{SiC}$ composite. After siliconization, any excess metallic silicon which remains on the surface of the product as beads is removed by sand blasting.

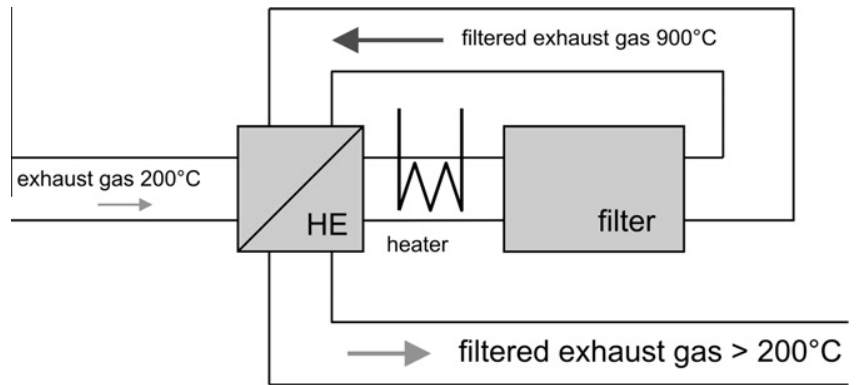

Fig. 2. Possible application of the proposed heat exchanger in diesel exhaust after treatment. 
Characterization for quality control of the honeycombs is done by through-flow testing, dimensional measurement, bulk density and mechanical strength.

\section{Methodology}

\subsection{Permeability}

Prior to the main experiments permeability investigations have been carried out. The diagram in Fig. 3 shows the specific pressure drop as a function of superficial velocity for both, the straight and the slotted channels of the HTHE sample. It underlines the increased pressure drop for the slotted channels because of the higher hydraulic resistance in the inlet cross-section. From these curves fits of the Darcy equation (1) have been generated for the determination of the permeability coefficients, which are summarized in Table 1

$-\frac{\Delta P}{l}=\frac{v \cdot \rho}{K_{1}} \cdot u+\frac{\rho}{K_{2}} \cdot u^{2}$

As expected, sample 2 shows higher permeability because of the larger channel diameter. However, due to the large difference in permeability properties it has been decided to investigate also the efficiency properties of the HTHE separately using the first fluid for the slotted channels and the second fluid for the straight channels and vice versa. The methodology in detail is described in the next section.

\subsection{Experimental set-up}

A metal canning (cross-box) was manufactured from high-alloyed steel to enclose the HTHE samples, which have cylindrical dimensions ( $\varnothing 68 \mathrm{~mm}$, length $100 \mathrm{~mm}$ ), for the experiments (Fig. 4, left). The mentioned two operation types of the HTHE are also illustrated in Fig. 4. The hot gas may firstly enter the straight channels and the cold gas the slotted channels (Fig. 4, center). This configuration is denoted with "type 1 ". The corresponding constellation vice versa is denoted with "type 2" (Fig. 4, right).

With the canning, four connections have been created for the integration of the HTHE samples into the piping of the experimental set-up as it is shown in Fig. 4. With a fan a controlled air flow through the whole piping can be generated. Mass flow is measured by monitoring the air temperature and the pressure difference at a standardized orifice. Before entering the HE in the cross-box, an electrical air heater can heat up the air to temperatures of up to

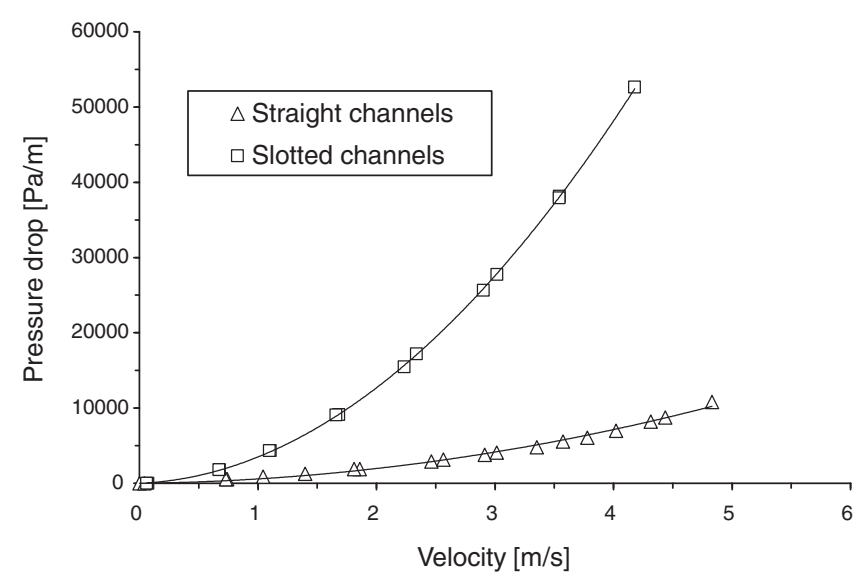

Fig. 3. Comparison of the pressure drop diagrams for the straight and slotted channels of the sample 2 .
Table 1

Permeability characteristics of the heat exchanger.

\begin{tabular}{|c|c|c|c|c|c|}
\hline & \multirow{2}{*}{$\begin{array}{l}\text { Pressure drop } \\
\text { during the main } \\
\text { experiments } \\
\text { (mbar) }\end{array}$} & \multicolumn{2}{|c|}{$\begin{array}{l}\text { Permeability } \\
\text { coefficient } K_{1}\left(\mathrm{~m}^{2}\right)\end{array}$} & \multicolumn{2}{|c|}{$\begin{array}{l}\text { Inertial coefficient } K_{2} \\
(\mathrm{~m})\end{array}$} \\
\hline & & Straight & Slotted & Straight & Slotted \\
\hline $\begin{array}{c}\text { Sample } \\
1\end{array}$ & $0.2-15$ & $2.7 \cdot 10^{-8}$ & $9.5 \cdot 10^{-9}$ & $4.5 \cdot 10^{-3}$ & $4.0 \cdot 10^{-4}$ \\
\hline $\begin{array}{c}\text { Sample } \\
2\end{array}$ & & $9.7 \cdot 10^{-8}$ & $2.7 \cdot 10^{-8}$ & $3.1 \cdot 10^{-3}$ & $4.4 \cdot 10^{-4}$ \\
\hline
\end{tabular}

$980{ }^{\circ} \mathrm{C}$. The experiments reported of have been carried out with a heater power $2.8 \mathrm{~kW}$. By varying the mass flow rate, different inlet temperatures are generated. After passing the primary channels of the HE the air is cooled down with a water cooler. Now, it enters the secondary channels of the HE and afterwards it leaves the set-up.

Temperatures at the 2 inlets and 2 outlets of the cross-box are measured with 2 thermocouples at each site. In the further course of the text these sites are denoted with TC1 and TC2 (in and outlet of the hot or primary fluid) and with TC3 and TC4 (in and outlet of the cold or secondary fluid). Additionally, the pressure difference along the primary and secondary channels of the HE sample was measured. Further sites of temperature measurements are denoted in Fig. 5. The Reynolds number did not exceed 160, hence laminar flow in the channels has been assumed.

Since the cross box consists of four parts, which are held together with screws, there is an additional option for temperature measurement: after removal of one of the four parts for an "open" operation this constellation allows an investigation of the local temperatures at the slotted as well as at the straight outlets of the HTHE via thermography.

\section{Theoretical basics and evaluation}

In this chapter the basic theory is presented, which has been used to predict the overall performance of the investigated heat exchanger. The results of the predictions are presented in Section 5 in comparison with the experimental results. There are two main equations for the calculation of the heat exchanger. Firstly the mass and heat balance equation:

$Q=W_{1} \cdot \delta t_{1}=W_{2} \cdot \delta t_{2}$

Using

$W_{i}=M_{i} \cdot c_{P i}$

as the heat capacity rate and $\delta t_{1}$ and $\delta t_{2}$ denoting the temperature difference between the in and outlet temperatures of the primary and secondary fluid respectively. Secondly, the basic heat transfer equation

$Q=k \cdot A \cdot \Delta \bar{T}$

using the Log Mean Temperature Difference $\Delta \bar{T}$, which is a function of the in- and outlet temperatures TC1 to TC4. Furthermore Eq. (2) uses the Overall Heat Transfer Coefficient $k$ [11]:

$k=\frac{1}{\frac{1}{\alpha_{1}}+\sum_{j=1}^{n} \frac{\delta_{j}}{\lambda_{j}}+\frac{1}{\alpha_{2}}}$

Since the superficial areas of the primary fluid channels and the secondary fluid channels are slightly different, the overall heat transfer coefficient for heat exchangers with different working surfaces of the heat carriers was calculated with the following equation: 

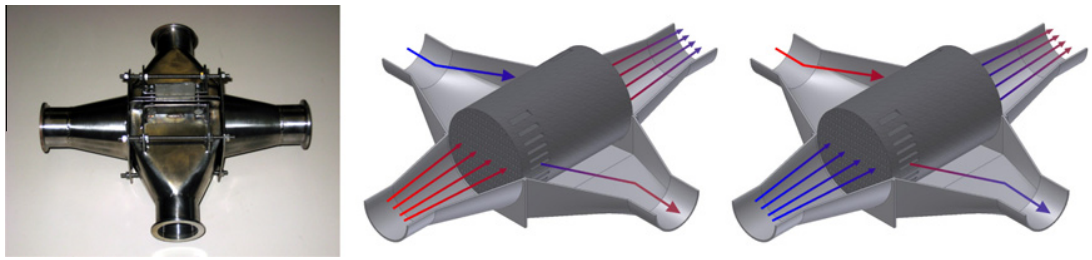

Fig. 4. Canning of the heat exchanger and the two operation types (type 1, center, type 2, right) schematically.

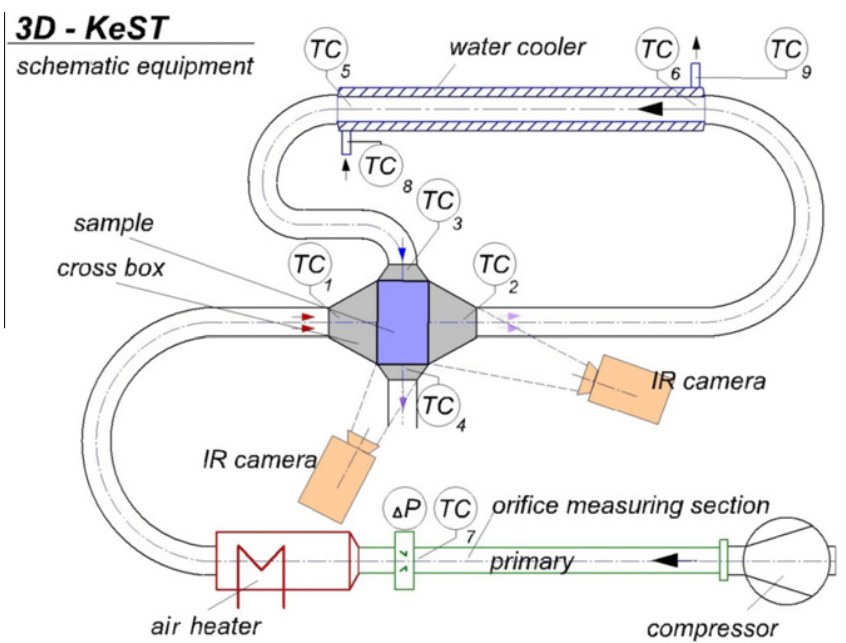

Fig. 5. Experimental set-up (type 2 operation).

$\bar{k} \cdot A_{0}=\frac{1}{\left(\frac{1}{A_{1} \cdot \alpha_{1}}+\frac{1}{A_{0}} \cdot \sum_{j=1}^{n} \frac{\delta_{j}}{\lambda_{j}}+\frac{1}{A_{2} \cdot \alpha_{2}}\right)}$

Taking into account the high thermal conductivity of silicon carbide $\left(150 \mathrm{~W} / \mathrm{m} \mathrm{K}\right.$ at $20^{\circ} \mathrm{C}, 30 \mathrm{~W} / \mathrm{m} \mathrm{K}$ at $\left.700^{\circ} \mathrm{C}\right)$ and the small wall dimensions the middle heat resistance in the denominator of equation (5) could be neglected. The values of the heat transfer surfaces $A_{1}$ and $A_{2}$ for the primary and secondary fluid channels are given in Table 2.

To calculate the convective heat transfer coefficients $\alpha_{1}$ and $\alpha_{2}$ the flow in the HE was considered as forced convection laminar flow. For these conditions an expression for the Nusselt-number is given by Stephan [12]:

$N u_{\mathrm{m}}=\frac{N u_{\mathrm{ma}}}{\tanh \left(2.432 \cdot \operatorname{Pr}^{1 / 3} \cdot X^{1 / 6}\right)} \quad$ here : $X=(L / d) \cdot(1 / P e)$

$N u_{\mathrm{ma}}=\frac{3.608}{\tanh \left(2.264 \cdot X^{1 / 3}+1,7 \cdot X^{2 / 3}\right)}+\frac{0.0499}{X} \cdot \tanh X$

Here $X=\left(L / d_{h}\right) \cdot(1 / P e)$.

From the Nusselt-numbers convective heat transfer coefficients were calculated with:
$\alpha=\frac{N u_{\mathrm{m}} \cdot \lambda}{d_{h}}$

However, the fluid properties thermal conductivity $\lambda$ and thermal diffusivity a, which occur in the Peclet Number definition, $P e=u l / a$ are temperature dependent. The calculation here has been done with the average temperatures.

With the overall heat transfer coefficients $\bar{k} \cdot A_{0}$ calculated for the different mass flow rates (see Table 2 ) it was possible to predict the outlet temperatures and to compare them with the experimental data. The following equations were used, which can be derived with a differential approach to be found in the standard literature [10-12]:

$\Delta t_{1}=\left(t_{1}^{\prime}-t_{2}^{\prime}\right) \cdot \frac{\left(1-\exp \left(-\bar{k} \cdot A_{0} \cdot\left(\frac{1}{W_{1}}-\frac{1}{W_{2}}\right)\right)\right)}{1-\frac{W_{1}}{W_{2}} \cdot \exp \left(-\bar{k} \cdot A_{0} \cdot\left(\frac{1}{W_{1}}-\frac{1}{W_{2}}\right)\right)}$

$\Delta t_{2}=\left(t_{1}^{\prime}-t_{2}^{\prime}\right) \cdot \frac{\left(1-\exp \left(-\bar{k} \cdot A_{0} \cdot\left(\frac{1}{W_{1}}-\frac{1}{W_{2}}\right)\right)\right)}{\frac{W_{2}}{W_{1}}-\exp \left(-\bar{k} \cdot A_{0} \cdot\left(\frac{1}{W_{1}}-\frac{1}{W_{2}}\right)\right)}$

The calculated outlet temperatures:

$t_{1}^{\prime \prime}=t_{1}^{\prime}-\Delta t_{1}, \quad t_{2}^{\prime \prime}=t_{2}^{\prime}-\Delta t_{2}$

Theoretical values of the heat flow have been determined with the thermal balance equation (2) using calculated values of the outlet temperatures from the equations (9) and (10).

Finally and with the objective to compare the performance of the HE with existing ones, its efficiency was calculated as a relation between the actual values of the heat flow to the maximum possible heat flow which corresponds to a HE with an infinite surface:

$\varepsilon=\frac{Q}{Q_{\infty}}$

In case of counter flow HE's this heat flow can be calculated from the inlet temperatures of the two fluids (note that in the case of the present study the heat capacity rates have been nearly equal, $\left.W_{1} \approx W_{2}\right)$ :

$Q_{\infty}=W_{\min } \cdot\left(t_{1}^{\prime}-t_{2}^{\prime}\right)$

The efficiency of HEs is most commonly given as a function of the number of transfer units (NTU):

$\mathrm{NTU}=\frac{k \cdot A_{0}}{W_{\min }}$

Table 2

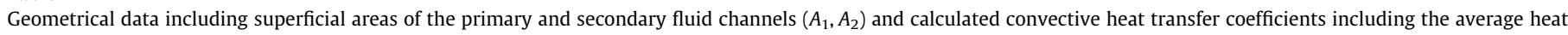
transfer coefficient of the investigated HE's.

\begin{tabular}{|c|c|c|c|c|c|c|c|c|}
\hline & Wall-thickness (mm) & Channel-width (mm) & $A_{1}\left(\mathrm{~m}^{2}\right)$ & $A_{2}\left(\mathrm{~m}^{2}\right)$ & Mass flow rate $(\mathrm{g} / \mathrm{s})$ & $\alpha_{1}\left(\mathrm{~W} / \mathrm{m}^{2} \mathrm{~K}\right)$ & $\alpha_{2}\left(\mathrm{~W} / \mathrm{m}^{2} \mathrm{~K}\right)$ & $\bar{k} A_{0}[\mathrm{~W} / \mathrm{K}]$ \\
\hline Sample 1 & 0.8 & 2 & 0.19 & 0.1 & $1.8-4.4$ & $94-96$ & $64-66$ & $4.7-4.9$ \\
\hline Sample 2 & 0.6 & 2.17 & 0.21 & 0.12 & $1.8-4.4$ & $86-89$ & $61-63$ & $5.2-5.4$ \\
\hline
\end{tabular}




\section{Results and discussion}

This chapter contains the experimental results in comparison with the calculated values. The basic heat transfer data used for the calculated values have been derived from the geometry of the HE samples. They are presented in Table 2. As can be seen, the improved heat transfer performance of the second HE sample can be directly related to the increased surface area due to the modified channel geometry.

The heat flow performance is shown in Fig. 8. As expected, heat flow increases with increasing mass-flow due to higher heat transfer coefficients for higher fluid flow velocities. A significant increase of heat flow for sample 2 and also for type 2-flow can be observed. The difference between the experimental and the calculated results is $25-38 \%$ for sample 1 and $10-25 \%$ for sample 2 .

Diagrams in Figs. 6 and 7 show the in- and outlet temperatures as a function of mass flow for the primary and the secondary heat carrier respectively. Since the experiments have been carried out with a constant power of the heater for the primary fluid and a varying mass flows. The inlet temperature of the primary fluid (white symbols) decreases with increasing mass flow. The experimental values of the outlet temperature (black symbols) remain almost constant. The calculated outlet temperatures (gray symbols) are significantly lower compared to the experimental ones. However, this deviation reaching $26-46 \%$ for sample 1 and $12-36 \%$ for sample 2 is not that astonishing, because the theoretical calculation does not take into account the flow distribution in the parallel ducts. This flow distribution may be non-homogenous due to the special situation at the in- and outlet of the slotted channels (Fig. 4).

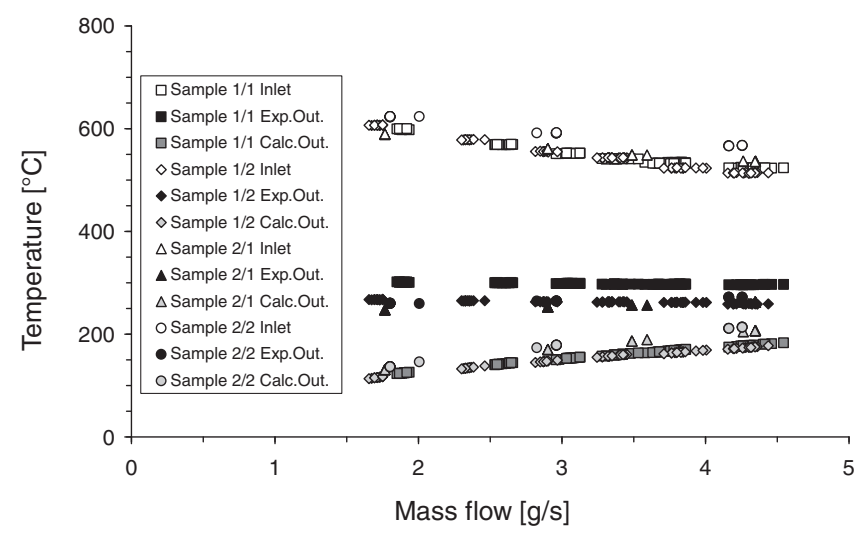

Fig. 6. Comparison of the temperatures of the primary fluid (e.g. sample $1 / 1$ means sample 1 type 1 flow).

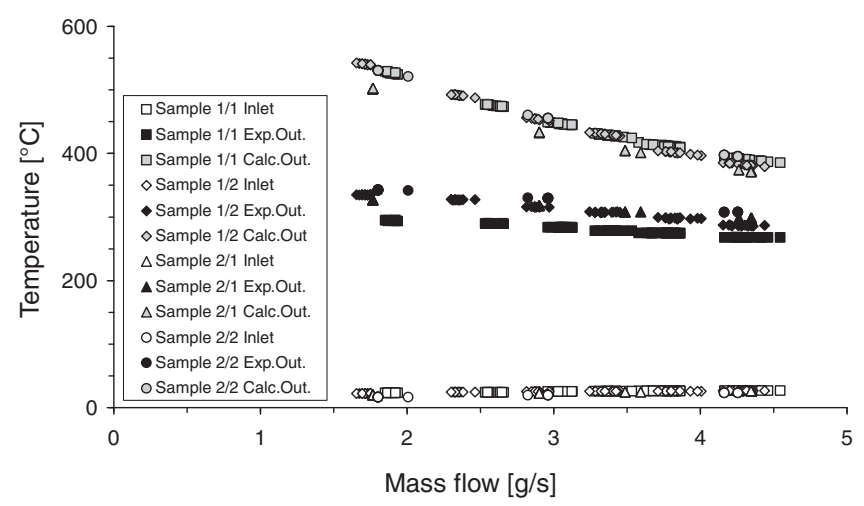

Fig. 7. Comparison of the temperatures of the secondary fluid.

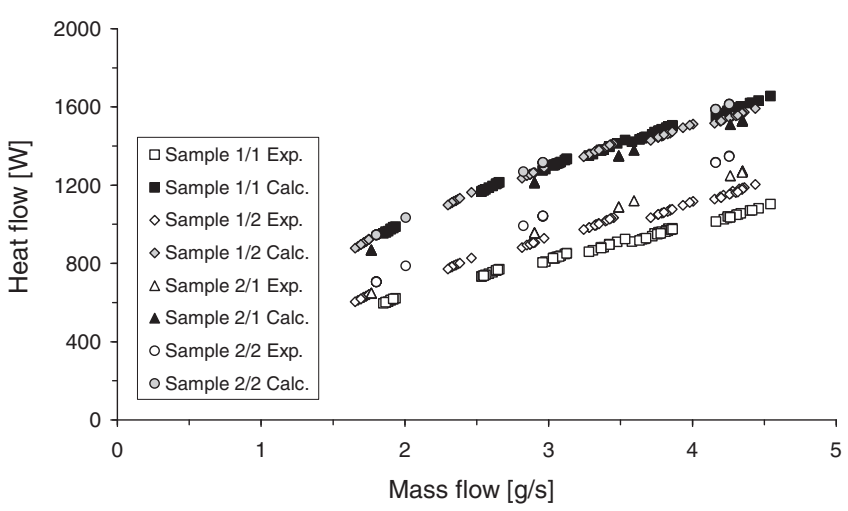

Fig. 8. Heat flow as a function of mass flow.

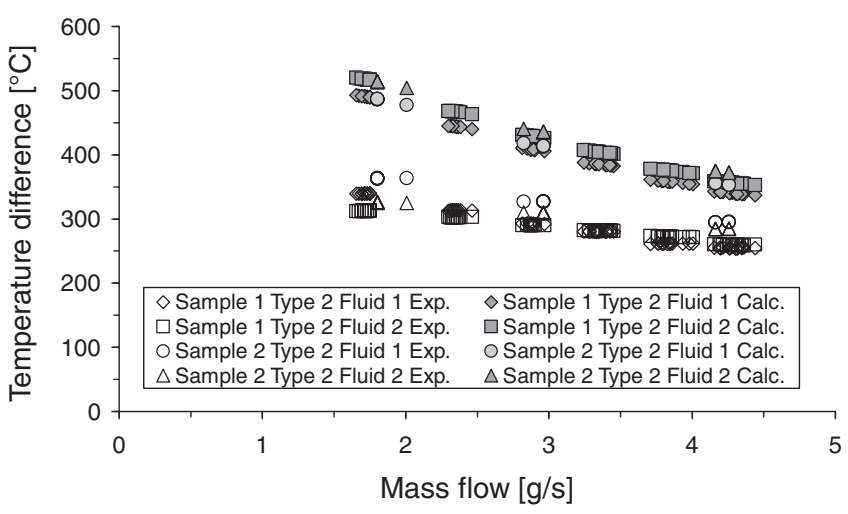

Fig. 9. Temperature difference as a function of mass flow for type 2 flow.

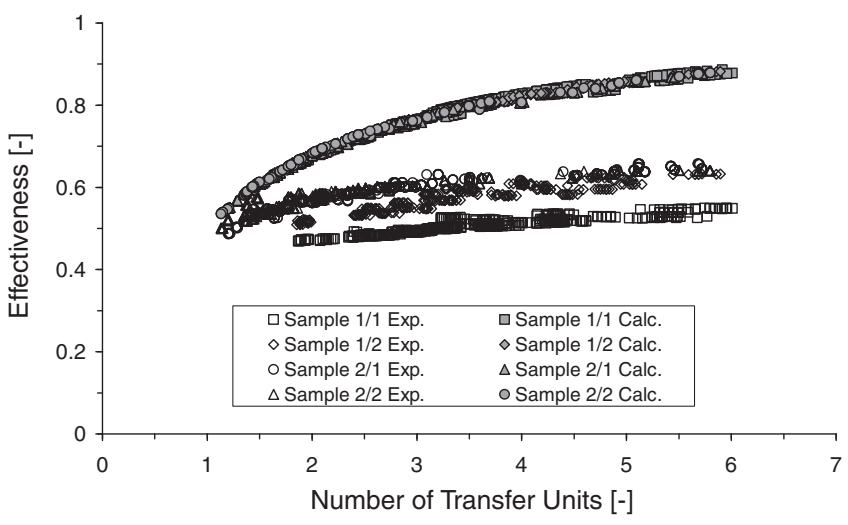

Fig. 10. Performance characteristic of the heat exchanger.

Here, we have to take into account, that the duct diameter is comparably small and the inlet flow direction of the slotted channels is perpendicular to the channel direction. Comparing the temperatures for a certain mass flow it may bee seen that sample 2 shows larger temperature differences, which means a slightly better performance. The temperature difference data (Fig 9) yields a similar deviation of the calculated values from the experimental ones.

Finally, Fig. 10 shows the performance characteristics of the heat exchanger, which enables a comparison with conventional ones and compact heat exchangers $[4,7,8]$. Effectiveness data are given as a function of number of heat transfer units. The effectiveness ranges from $48 \%$ to $62 \%$ for sample 1 and from $50 \%$ to $65 \%$ 
for sample 2. Additionally it becomes obvious also in terms of effectiveness that the second sample shows a significantly improved performance.

As examples, the following comparison with conventional and high performance heat exchangers is given: Aqauro and Pieve report efficiencies of high temperature compact gas/gas heat exchangers of up to $62 \%$ [8]. Jiang et al. have published efficiencies of micro-channel and porous media water heat exchangers with a total surface area density of $2895 \mathrm{~m}^{2} / \mathrm{m}^{3}$ and $5011 \mathrm{~m}^{2} / \mathrm{m}^{3}$ of up to $50 \%$ and $66 \%$ correspondingly [7]. Finally, Brandner reported results of micro-channel water heat exchangers with mechanically cut and chemically etched microstructure foil and total surface area densities of approximately $30,000 \mathrm{~m}^{2} / \mathrm{m}^{3}$. Efficiencies of $80 \%$ and $68 \%$ respectively have been reached [4]. The efficiency of the proposed compact heat exchanger corresponds well to the mentioned one taking into consideration the heat transfer medium.

Compared to conventional counter current heat exchangers with similar values of specific surface area, which offer typical effectiveness values of up to 60\% [11], the performance of the present compact $\mathrm{SiC}$ high temperature heat exchanger investigated in the present study is quite well.

To investigate the local temperature distribution at the two outlet cross-sections of the HE sample thermography investigations
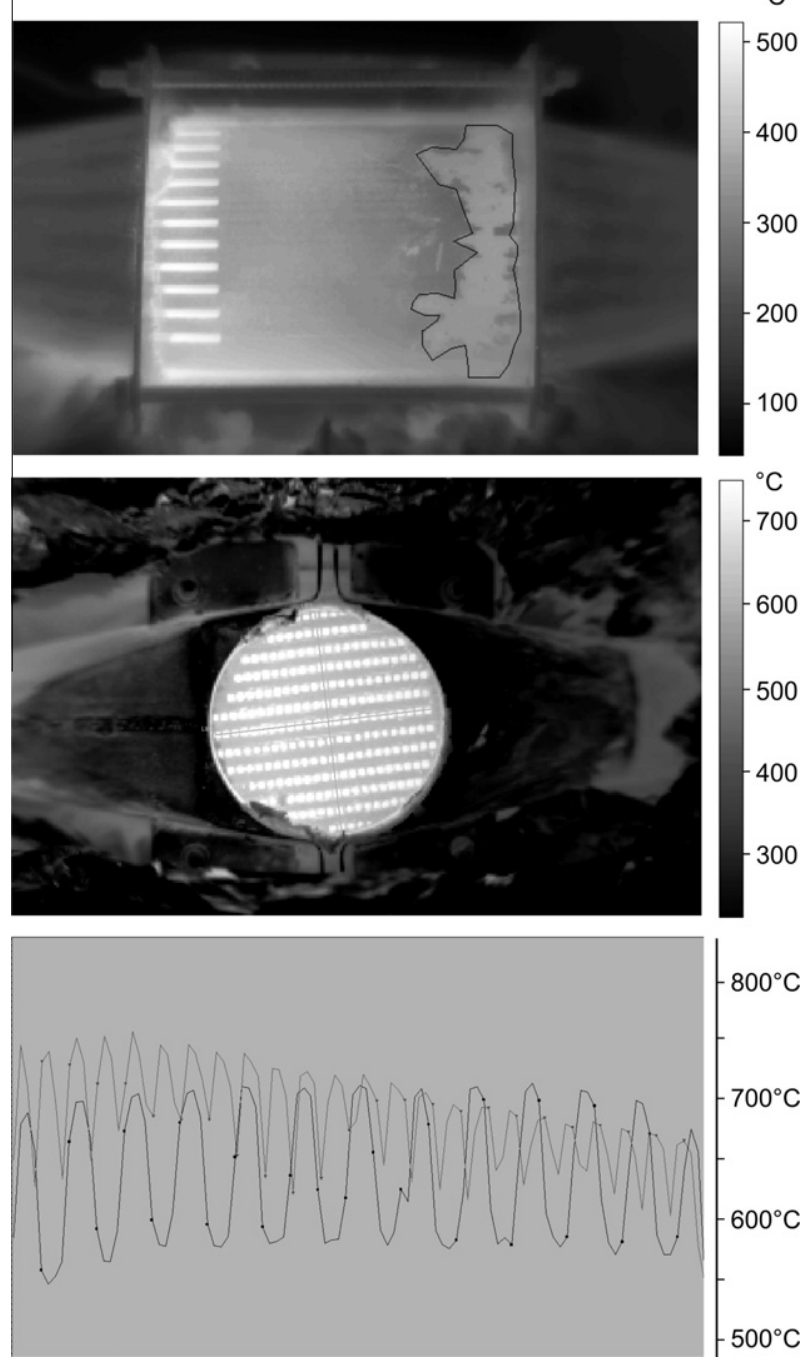

Fig. 11. Temperature data of the HTHE during operation in type 1 configuration from thermograph measurements. have been performed. During the measurements the HE has been in type 1 operation. The IR-cameras were put in the positions according to the sketch in Fig. 5. In Fig 11, the results are shown. The picture at the top shows the outlet of the second fluid during a "high temperature test". During the test the heater was operated at maximum power which led to inlet temperatures of the first fluid of $930-950{ }^{\circ} \mathrm{C}$. The picture below shows the outlet of the primary fluid in an operation mode, where no second fluid was employed.

Both infrared shots were taken at stationary conditions. The temperature shows a quite homogenous distribution. The region on the right at the top picture (encircled with the black line) is slightly hotter, because this is the region where the lateral openings have been sealed with ceramic kit.

On the diagram at the bottom of Fig. 11 the stationary local temperature distribution on the front side depicted in the Fig. 11 (center) is given. The upper curve with the smaller difference between maximum and minimum temperatures belongs to the horizontal line on Fig. 11 (light gray curve) and other curve belongs to the vertical one. The local maximum values on this diagram are temperatures close to those inside the channels and the minimum values are close the front wall temperatures. An analysis of these curves yields a maximum temperature difference between neighboring channels of 10 and $18{ }^{\circ} \mathrm{C}$. The maximum temperature difference between the front wall temperature and the temperature inside the channel reaches $40{ }^{\circ} \mathrm{C}$ in the vertical direction and $80^{\circ} \mathrm{C}$ in the horizontal one. This non-homogeneous distribution of the temperature is due to a non-homogeneous distribution of fluid velocity in the channels, which is considered to be the main reason for the difference in performance between calculated and experimental data.

\section{Conclusions}

The experiments confirmed the high reliability of the HE during operation at temperatures of up to $950{ }^{\circ} \mathrm{C}$. Deviations of the experimental results from the calculated ones are probably due to large differences between local temperatures and velocities, which have been revealed by thermograph investigation. The second HE sample showed better heat exchange performance due to smaller wall dimensions. The investigated HE-material can be recommended for applications at high temperatures of at least $950{ }^{\circ} \mathrm{C}$. Tests at higher temperatures should be performed to explore the temperature range beyond this value. The investigated HE provides good effectiveness performance of up to $65 \%$. It exhibits an excellent compact geometry with a surface to heat transfer surface/volume ratio of $995 \mathrm{~m}^{3} / \mathrm{m}^{2}$. Further experimental tests will be carried out to investigate the local temperature distributions. By means of numerical fluid dynamics and heat transfer further calculations will be performed to have a closer match to the experimental results. Furthermore, the HE will be tested together with a diesel particle filter (DPF) in an engine test to demonstrate fuel saving during the regeneration process of the DPF.

\section{Acknowledgements}

This study was part of the project "Three-dimensional ceramic structures for various Innovative Applications (3D-KeSt)", which was funded by the German" Federal Ministry of Education and Research". The support of the Ministry is gratefully acknowledged.

\section{References}

[1] J. Adler, Ceramic diesel particulate filters, Int. J. Appl. Ceram. Technol. 2 (6) (2005) 429-439.

[2] H.D. Tietz, Technical Thermodynamic, VDI, Düsseldorf, 1994. 
[3] Th. Fend, R. Pitz-Paal, B. Hoffschmidt, O. Reutter, Solar radiation conversion, in: M. Scheffler, P. Colombo, (Eds.), Cellular Ceramics: Structure, Manufacturing Properties and Applications, Wiley-VCH Verlag GmbH \& Co., KgaA, Weinheim, 2005.

[4] J.J. Brandner, E. Anurjew, L. Bohn, E. Hansjosten, T. Henning, U. Schygulla, A Wenka, K. Schubert, Concepts and realization of microstructure heat exchangers for enhanced heat transfer, Exp. Therm. Fluid Sci. 30 (2006) 801809.

[5] J.J. Brandner, L. Bohn, T. Henning, U. Schygulla, K. Schubert, Microstructure heat exchanger applications in laboratory and industry, Heat Transfer Eng. 28 (8-9) (2007) 761-771.

[6] J.J. Brandner, Microfabrication in metals and polymers, Adv. Micro- Nanosyst. 5 (2006) 267-320.

[7] P.-X. Jiang, M.-H. Fan, G.-S. Si, Z.-P. Ren, Thermal-hydraulic performance of small scale micro-channel and porous-media heat exchangers, Int. J. Heat Mass Transfer 44 (2001) 1039-1051.
[8] D. Aquaro, M. Pieve, High temperature compact heat exchangers performance of advanced metallic recuperators for power plants, in: Proceedings of Fifth International Conference on Enhanced, Compact and Ultra-Compact Heat Exchangers, NJ, USA, September 2005.

[9] G.K. Housley, J.E. O'Brien, G.L. Hawkes, Design of a compact heat exchanger for heat recuperation from a high temperature electrolysis system, in: Proceedings of the 2008 International Mechanical Engineering Congress and exposition, Boston, Massachusetts, USA, 2008.

[10] Verein Deutscher Ingenieure VDI-Gesellschaft Verfahrenstechnik und Chemieingenieurwesen (GVC), VDI-Wärmeatlas, 10 Auflage, Springer-Verlag, Berlin-Heidelberg, 2006.

[11] F. Kreith, M.S. Bohn, Principles of Heat Transfer, Thomson, London, 2001.

[12] H.D. Baehr, K. Stefan, Wärme- und Stoffübertragung, Springer-Verlag, Berlin, Heidelberg, 2006 